\section{Re: First Trimester Procedural Abortion in Family Medicine}

To the Editor: I read with some disbelief the statement cited by Lyus et $\mathrm{al}^{1}$ that "almost half" of American women will have had an abortion.

Following the first reference (to the Guttmacher Institute website), the national overview presently states: "At current rates, about one in three American women will have had an abortion by the time she reaches age 45."2

There is an obvious bias to inflate figures about abortion in an article on abortion! Nevertheless, I was caught by surprise to find abortion so prevalent, as this statistic does not match what my patients either have had, or perhaps, are willing to reveal to me.

While New York State data were the referenced source, there are significant regional differences. In fact, the abortion rate for New York state in 2005 was almost exactly twice the national average, whereas here in Texas our rate was lower than the national average. ${ }^{2,3}$

Gordon Uretsky, MD

Tatum Medical Clinic

Tatum, Texas

tmc.doctor@tatumtel.net

\section{References}

1. Lyus RJ, Gianutsos P, Gold M. First trimester procedural abortion in family medicine. J Am Board Fam Med 2009; 22:169-74.

2. Guttmacher Institute. State facts about abortion: New York. Available from http://www.guttmacher.org/pubs/sfaa/new_ york.html. Accessed 1 June 2009.

3. Guttmacher Institute. State facts about abortion: Texas. Available from http://www.guttmacher.org/pubs/sfaa/ texas.html. Accessed 1 June 2009.

doi: 10.3122/jabfm.2009.06.090138

The above letter was referred to the author of the article in question, who offers the following reply.

\section{Response: Re: First Trimester Procedural Abortion in Family Medicine}

To the Editor: We appreciate the interest of Dr. Uretsky ${ }^{1}$ in abortion and apologize for the error in the abstract. The correct proportion of women having an abortion is as stated in the first paragraph of the article ${ }^{2}$ : "at least one-third of women will have an abortion." However, he incorrectly states that the Guttmacher references New York data. In fact, the data cited in the Guttmacher reference ${ }^{3}$ are derived from the 2002 National Survey of Family Growth and were combined with birth, abortion, and population data from federal, state, and nongovern- mental sources to arrive at the estimates. No attempt has been made to inflate the figures regarding abortion; rather, a careful reading of the article demonstrates the widespread prevalence of abortion and the need for family doctors to provide this service to their patients.

L. Paul Gianutsos, MD, MPH

Swedish Family Medicine Residency Cherry Hill

Seattle, Washington paul.gianutsos@swedish.org

\section{References}

1. Uretsky G. Re: first trimester procedural abortion in family medicine. J Am Board Fam Med 2009;22:707.

2. Lyus RJ, Gianutsos P, Gold M. First trimester procedural abortion in family medicine. J Am Board Fam Med 2009; 22:169-74.

3. Guttmacher Institute. In brief: facts on induced abortion in the United States. Available from http://www.guttmacher. org/pubs/fb_induced_abortion.html. Accessed 29 December 2008

doi: 10.3122/jabfm.2009.06.090201

\section{Re: Prostate-Specific Antigen Testing among the Elderly in Community-Based Family Medicine Practices}

To the Editor: I read with interest the original research article, "Prostate-Specific Antigen Testing among the Elderly in Community-Based Family Medicine Practices," by Hudson et al. ${ }^{1}$ Doctor-directed clinical activities that are unsupported by medical evidence and ignore credible guidelines can be summed up in 2 words: thoughtless practice. Some of the harms that follow thoughtless screening practices include:

- Lost opportunities: doctor-patient interactions that stray into inappropriate screening risk missing opportunities to focus on more useful testing or to bypass screening in favor of directly providing effective preventive services.

- High rate of false-positive results: screening tests reveal incidental "abnormal" results that lead to patient anxiety, false diagnostic labeling, and more testing that compounds risk and increases costs.

- Impracticality: the discovery of disease that cannot be modified or disease in the presence of treatment-limiting comorbidities is unlikely to alter the extent or quality of a patient's life, and because of treatment side effects and risks, may decrease both.

- Diversion of resources: no matter how distant the consequences of inappropriate testing may seem, health care 